\title{
Effect of Multiple Prior Percutaneous Coronary Interventions on Outcomes After Coronary Artery Bypass Grafting
}

\author{
Keisuke Hakamada, MD; Genichi Sakaguchi, MD, PhD; Akira Marui, MD, PhD; \\ Yoshio Arai, MD, PhD; Atsushi Nagasawa, MD, PhD; Shinichi Tsumaru, MD, PhD; \\ Michiya Hanyu, MD, PhD; Yoshiharu Soga, MD, PhD
}

\begin{abstract}
Background: The effect of multiple prior percutaneous coronary interventions (PCls) before subsequent coronary artery bypass grafting (CABG) on long-term outcomes has not been well elucidated.

Methods and Results: Between 2007 and 2016, 1,154 patients undergoing primary isolated CABG in our institution had no prior $\mathrm{PCl}$ (Group N), 225 had a single prior PCl (Group S), and 272 had multiple prior PCls (Group M). Cumulative incidences of all-cause death, cardiac death and myocardial infarction (MI) at 10 years post-CABG were highest in Group M. After adjusting for confounders, the risk of all-cause death was higher in Group M than in Group N (hazard ratio [HR] 1.45; 95\% confidence interval [Cl], 1.10-1.91; $\mathrm{P}<0.01$ ). Between Groups $\mathrm{N}$ and $\mathrm{S}$, however, the risk of all-cause death was not different. The risks of cardiac death and $\mathrm{MI}$ were likewise higher in Group M than in Group N (HR, 2.39; 95\% Cl, 1.55-3.71; $\mathrm{P}<0.01$ and HR, 3.65; 95\% Cl, 1.16-11.5; $\mathrm{P}=0.03$, respectively), but not different between Groups $\mathrm{N}$ and $\mathrm{S}$. The risk of repeat revascularization was not different among any of the groups.
\end{abstract}

Conclusions: Multiple prior PCls was associated with higher risks of long-term death and cardiovascular events. The incidence of repeat revascularization after CABG was low regardless of the history of single/multiple PCls.

Key Words: Coronary artery bypass grafting; Coronary artery disease; Percutaneous coronary intervention

$\mathbf{S}$ ince the introduction of drug-eluting stents (DES), the worldwide incidence of percutaneous coronary intervention (PCI) with initial and repeated therapy for coronary artery disease (CAD) has rapidly increased. As the frequency of PCI has increased, the numbers of patients who are referred for coronary artery bypass grafting $(\mathrm{CABG})$ after multiple prior PCIs have also increased. According to the Society of Thoracic Surgeons 2018 Adult Cardiac Surgery Database, $28.9 \%$ of patients who underwent isolated CABG had prior histories of PCIs. ${ }^{1}$ This figure is larger than that reported a decade previously, and the numbers of patients with multiple prior PCIs are likely to continue to increase in future. A possible adverse effect of prior PCI on early and mid-term outcomes after subsequent CABG has been reported, ${ }^{2-4}$ but the question of whether multiple prior PCIs might also influence long-term outcomes after subsequent CABG has not been thoroughly explored. As investigators in most previous reports have divided patients into 2 groups, those with and those without prior PCI, the effect of multiple prior PCIs has not been clearly distinguished from that of a single prior PCI. Thus, the aim of our study was to investigate the effect of multiple prior PCIs on long-term outcomes after subsequent CABG.

\section{Methods}

\section{Study Population}

This study was a retrospective single-center cohort study. This study was approved by the institutional review board of Kokura Memorial Hospital. A total of 1,708 patients underwent primary CABG at our institution between January 2007 and December 2016. Patients with a history of prior CABG (7 patients), cardiogenic shock complicating acute myocardial infarction (MI) or PCI failure (20 patients), and concomitant mitral valve surgery for ischemic mitral regurgitation (30 patients) were excluded. Overall, 1,651 patients were included in this study. Patients were divided into 3 groups according to whether they had no prior PCI procedures (Group N, n=1,154 [69.9\%]), a successful single prior PCI procedure (Group S, $n=225$ $[13.6 \%]$ ) or multiple prior PCI procedures (Group M, n=272 $[16.5 \%]$ ) before CABG (among the 30 patients excluded due to concomitant mitral valve surgery for ischemic mitral

Received May 29, 2020; revised manuscript received September 17, 2020; accepted October 22, 2020; J-STAGE Advance Publication released online December 19, 2020 Time for primary review: 21 days

Department of Cardiovascular Surgery, Kokura Memorial Hospital, Fukuoka (K.H., A.M., Y.A., A.N., S.T., Y.S.); Department of Cardiovascular Surgery, Kindai University, Osaka (G.S.); and Department of Cardiovascular Surgery, Kitano Hospital, Osaka (M.H.), Japan

Mailing address: Keisuke Hakamada, MD, Department of Cardiovascular Surgery, Kokura Memorial Hospital, 3-2-1 Asano, Kokurakita-ku, Kitakyusyu 802-8555, Japan. E-mail: hakamada@kuhp.kyoto-u.ac.jp

All rights are reserved to the Japanese Circulation Society. For permissions, please e-mail: cj@j-circ.or.jp

ISSN-1346-9843 


\begin{tabular}{|c|c|c|c|c|}
\hline Variables & $\begin{array}{c}\text { Group N } \\
(n=1,154)\end{array}$ & $\begin{array}{c}\text { Group S } \\
(n=225)\end{array}$ & $\begin{array}{c}\text { Group M } \\
(n=272)\end{array}$ & $P$ value \\
\hline Age, years & $69 \pm 9.3$ & $69 \pm 9.7$ & $68 \pm 8.9$ & 0.17 \\
\hline \multicolumn{5}{|l|}{ Gender } \\
\hline Male & $861(74.6)$ & $177(78.7)$ & $215(79.0)$ & 0.18 \\
\hline Female & $293(25.4)$ & $48(21.3)$ & $57(21.0)$ & 0.18 \\
\hline Body mass index $\left(\mathrm{kg} / \mathrm{m}^{2}\right)$ & $24 \pm 3.5$ & $24 \pm 2.9$ & $24 \pm 3.4$ & 0.33 \\
\hline $\mathrm{BMI}>25$ & 403 (34.9) & $83(36.9)$ & $112(41.2)$ & 0.15 \\
\hline $\mathrm{BMI}<18.5$ & $50(4.3)$ & $5(2.2)$ & $8(2.9)$ & 0.23 \\
\hline Hypertension & $919(79.6)$ & $181(80.4)$ & $229(84.2)$ & 0.23 \\
\hline Dyslipidemia & $781(67.7)$ & $159(70.7)$ & 201 (73.9) & 0.12 \\
\hline Diabetes mellitus & $606(52.5)$ & $101(44.9)$ & $153(56.3)$ & 0.04 \\
\hline Diabetes with insulin & $179(15.5)$ & $30(13.3)$ & $41(15.1)$ & 0.71 \\
\hline \multicolumn{5}{|l|}{ Renal disease } \\
\hline Serum creatinine (mg/dL) & $1.5 \pm 2.0$ & $1.5 \pm 2.0$ & $2.3 \pm 3.0$ & $<0.01$ \\
\hline Estimated GFR (mL/min/1.73 $\left.\mathrm{m}^{2}\right)$ & $59 \pm 24$ & $57 \pm 23$ & $51 \pm 27$ & $<0.01$ \\
\hline Chronic kidney disease & $545(47.2)$ & $114(50.7)$ & $163(59.9)$ & $<0.01$ \\
\hline Hemodialysis & $86(7.5)$ & $17(7.6)$ & $43(15.8)$ & $<0.01$ \\
\hline Prior stroke & $201(17.4)$ & $35(15.6)$ & $46(16.9)$ & 0.79 \\
\hline Prior myocardial infarction & $254(22.0)$ & $91(40.4)$ & $87(32.0)$ & $<0.01$ \\
\hline Congestive heart failure & $180(15.6)$ & $29(12.9)$ & $37(13.6)$ & 0.47 \\
\hline Unstable angina & $333(28.9)$ & $59(26.2)$ & $74(27.2)$ & 0.67 \\
\hline Preoperative IABP & $144(12.5)$ & $18(8.0)$ & $23(8.5)$ & 0.04 \\
\hline \multicolumn{5}{|l|}{ Urgency of procedure } \\
\hline Elective & 945 (81.9) & $193(85.8)$ & $233(85.7)$ & 0.16 \\
\hline Urgent & $64(5.5)$ & $13(5.8)$ & $16(5.9)$ & 0.97 \\
\hline Emergency & $145(12.6)$ & $19(8.4)$ & $23(8.5)$ & 0.05 \\
\hline \multicolumn{5}{|l|}{ Smoking status } \\
\hline Ex-smoker & $620(53.7)$ & $135(60.0)$ & $149(54.8)$ & 0.22 \\
\hline Current smoker & $231(20.0)$ & $45(20.0)$ & $34(12.5)$ & 0.02 \\
\hline Chronic lung disease & $55(4.8)$ & $9(4.0)$ & $12(4.4)$ & 0.87 \\
\hline Peripheral artery disease & $125(10.8)$ & $30(13.3)$ & $40(14.7)$ & 0.15 \\
\hline Atrial fibrillation & $29(2.5)$ & $8(3.6)$ & $8(2.9)$ & 0.66 \\
\hline Ejection fraction (\%) & $57 \pm 14$ & $57 \pm 14$ & $54 \pm 14$ & $<0.01$ \\
\hline Left ventricular systolic dysfunction & $193(16.7)$ & $32(14.2)$ & $53(19.5)$ & 0.29 \\
\hline \multicolumn{5}{|l|}{ CCS angina status } \\
\hline I & $311(26.9)$ & 75 (33.3) & $59(21.7)$ & 0.01 \\
\hline II & $536(46.4)$ & $105(46.7)$ & $145(53.3)$ & 0.12 \\
\hline III & $177(15.3)$ & $32(14.2)$ & $42(15.4)$ & 0.91 \\
\hline IV & $130(11.3)$ & $13(5.8)$ & $26(9.6)$ & 0.04 \\
\hline \multicolumn{5}{|l|}{ NYHA functional class } \\
\hline I & $656(56.8)$ & $140(62.2)$ & $155(57.0)$ & 0.32 \\
\hline II & 341 (29.5) & $68(30.2)$ & $89(32.7)$ & 0.59 \\
\hline III & $91(7.9)$ & $9(4.0)$ & $12(4.4)$ & 0.03 \\
\hline IV & $66(5.7)$ & $8(3.6)$ & $16(5.9)$ & 0.40 \\
\hline
\end{tabular}

Data are presented as number (\%) or mean \pm standard deviation. Group N, no prior percutaneous coronary intervention (PCI); Group S, single prior PCl; Group M, multiple prior PCls. CCS, Canadian Cardiovascular Society; GFR, glomerular filtration rate; IABP, intra-aortic balloon pumping; NYHA, New York Heart Association.

regurgitation, 15 patients had no prior PCI, 6 patients had a single PCI, and 9 patients had multiple prior PCIs before $\mathrm{CABG})$. There was no patient undergoing $\mathrm{CABG}$ with left ventricular reconstruction. Before the operation, each patient granted permission for the use of his/her medical records for research purposes and written informed consent was obtained.

\section{Data Collection and Definitions}

Demographic, angiographic and procedural data were collected from hospital charts and databases. Follow-up data were obtained through either review of hospital records or a scripted telephone interview with referring physicians and patients.

Baseline patient characteristics such as hypertension, dyslipidemia, diabetes mellitus, smoking status, prior MI, congestive heart failure, atrial fibrillation, and chronic lung 


\begin{tabular}{|c|c|c|c|c|}
\hline Variables & $\begin{array}{c}\text { Group N } \\
(n=1,154)\end{array}$ & $\begin{array}{c}\text { Group S } \\
(n=225)\end{array}$ & $\begin{array}{c}\text { Group M } \\
(n=272)\end{array}$ & $P$ value \\
\hline Number of PCls & 0 & 1 & $3.6 \pm 2.1$ & $<0.01$ \\
\hline \multicolumn{5}{|l|}{ Extent of CAD } \\
\hline Left main disease & $488(42.3)$ & $104(46.2)$ & $135(49.6)$ & 0.07 \\
\hline 3 vessel disease & $799(69.2)$ & $122(54.2)$ & $143(52.6)$ & $<0.01$ \\
\hline 2 vessel disease & $259(22.4)$ & $80(35.6)$ & $96(35.3)$ & $<0.01$ \\
\hline 1 vessel disease & $63(5.5)$ & $17(7.6)$ & $22(8.1)$ & 0.18 \\
\hline Stent type & & & & $<0.01$ \\
\hline BMS & 0 & $132(58.7)$ & $176(64.7)$ & \\
\hline DES & 0 & $70(31.1)$ & $162(59.6)$ & \\
\hline Both BMS + DES & 0 & 0 & $71(26.1)$ & \\
\hline Unreported & 0 & $23(10.2)$ & $6(2.2)$ & \\
\hline Target vessels of prior $\mathrm{PCl}$ & & & & $<0.01$ \\
\hline Left descending artery & 0 & $77(34.2)$ & $208(76.5)$ & \\
\hline Left circumflex artery & 0 & $33(14.7)$ & $153(56.3)$ & \\
\hline Right coronary artery & 0 & $110(48.9)$ & $193(71.0)$ & \\
\hline Left main trunk & 0 & $5(2.2)$ & $11(4.0)$ & \\
\hline Indication for CABG & & & & $<0.01$ \\
\hline In-stent restenosis & 0 & $41(18.2)$ & $138(50.7)$ & \\
\hline De novo stenosis & 0 & $205(91.1)$ & $214(78.7)$ & \\
\hline Combined & 0 & $21(9.3)$ & $70(25.7)$ & \\
\hline Interval from initial $\mathrm{PCI}$ to $\mathrm{CABG}$ & - & $4.1 \pm 5.6$ & $8.0 \pm 6.9$ & $<0.01$ \\
\hline
\end{tabular}

Data are presented as number (\%) or mean \pm standard deviation. Group N, no prior PCl; Group S, single prior PCl; Group M, multiple prior PCls. BMS, bare metal stent; CABG, coronary artery bypass grafting; CAD, coronary artery disease; $\mathrm{DES}$, drug-eluting stent; $\mathrm{PCl}$, percutaneous coronary intervention.

disease were regarded as present when these diagnoses were recorded in the hospital charts or databases. Prior stroke was regarded as present when the diagnosis was made by a consultant neurologist. Peripheral artery disease was regarded as present even if it had already been treated by surgical or endovascular interventions. Chronic kidney disease was regarded as present when creatinine clearance, estimated according to the Cockcroft-Gault formula, was $<60 \mathrm{~mL} / \mathrm{min}$. Left ventricular ejection fraction (LVEF) was measured by echocardiography. The experienced operators in our institution performed M-mode and/or 2-dimensional echocardiography; M-mode LVEF was calculated using the Teichholz correction and 2-dimensional echocardiographic LVEF was measured by using the Simpson biplane method. Patients with LVEF $<40 \%$ were considered to have LV systolic dysfunction.

Cardiac death was defined as any cardiac-related or sudden death. MI was defined according to the Fourth Universal Definition of Myocardial Infarction (2018). Stroke was defined as hemorrhagic or ischemic stroke requiring hospitalization. Traumatic stroke was excluded. Repeat revascularization was defined as revascularization including PCI or re-CABG because of ischemic symptoms or electrocardiographic changes.

\section{Study Endpoints}

Early Outcomes We investigated operative mortality and major morbidity. Operative mortality was defined as death occurring within 30 days after the operation or any death during the index hospitalization. Major morbidity was defined as stroke within 30 days after the operation, reoperation for bleeding and deep sternal infection.

Long-Term Outcomes The primary endpoint was all-cause death. The secondary endpoints were cardiac death, MI, and repeat coronary revascularization.

\section{Statistical Analyses}

Data are presented as values, percentages and mean \pm standard deviation (SD). Regarding the baseline characteristics, categorical variables among the 3 groups were compared using a chi-squared test. Also, continuous variables among the 3 groups were compared using an ANOVA test.

After the descriptive statistics, cumulative incidence was estimated by using the Kaplan-Meier method, and differences were assessed with the log-rank test. Data on patients who were lost to follow up were censored. We used multivariate Cox proportional hazards models to assess the effects of multiple prior PCIs on death and cardiovascular events. Cox proportional hazards models were adjusted for the following confounders: age, gender, body mass index, hypertension, dyslipidemia, diabetes mellitus, chronic kidney disease, hemodialysis, prior stroke, prior MI, congestive heart failure, unstable angina, preoperative intra-aortic balloon pumping, urgency of procedure, smoking status, chronic lung disease, peripheral artery disease, atrial fibrillation, left ventricular systolic dysfunction, left main disease, 3-vessel disease, 2-vessel disease, 1-vessel disease, CCS 3-4, and NYHA 3-4. We calculated the hazard ratios (HRs) of Group M and Group S for Group N, considering the clinical importance and bias of baseline characteristics comprehensively.

Statistical analyses were performed using SPSS software version 24.0 (IBM Corporation, NY, USA). The authors had full access to the data and take responsibility for its integrity. 


\begin{tabular}{|c|c|c|c|c|}
\hline Variables & $\begin{array}{l}\text { Group N } \\
(n=1,154)\end{array}$ & $\begin{array}{l}\text { Group S } \\
(n=225)\end{array}$ & $\begin{array}{c}\text { Group M } \\
(n=272)\end{array}$ & $P$ value \\
\hline \multicolumn{5}{|l|}{ Operation } \\
\hline Off-pump CABG & $1,121(97.1)$ & $216(96.0)$ & 269 (98.9) & 0.13 \\
\hline On-pump beating CABG & $32(2.8)$ & $8(3.6)$ & $3(1.1)$ & 0.19 \\
\hline On-pump CABG & $1(0.1)$ & $1(0.4)$ & $0(0)$ & 0.30 \\
\hline \multicolumn{5}{|l|}{ Use of intrathoracic artery } \\
\hline Bilateral & $396(34.3)$ & $91(40.4)$ & $102(37.5)$ & 0.17 \\
\hline Single & $714(61.9)$ & $128(56.9)$ & $164(60.3)$ & 0.36 \\
\hline None & $44(3.8)$ & $6(2.7)$ & $7(2.6)$ & 0.43 \\
\hline Use of right gastroepiploic artery & $114(9.9)$ & $30(13.3)$ & $17(6.3)$ & 0.03 \\
\hline Distal anastomoses $(n)$ & $3.2 \pm 1.0$ & $3.0 \pm 1.0$ & $2.8 \pm 0.9$ & $<0.01$ \\
\hline
\end{tabular}

Data are presented as number (\%) or mean \pm standard deviation. Group N, no prior percutaneous coronary intervention (PCI); Group S, single prior PCl; Group M, multiple prior PCls. CABG, coronary artery bypass grafting.

\begin{tabular}{|c|c|c|c|c|}
\hline Outcomes & $\begin{array}{c}\text { Group N } \\
(n=1,154)\end{array}$ & $\begin{array}{c}\text { Group S } \\
(n=225)\end{array}$ & $\begin{array}{c}\text { Group M } \\
(n=272)\end{array}$ & $P$ value \\
\hline Operative mortality & $11(1.0)$ & $2(0.9)$ & $5(1.8)$ & 0.43 \\
\hline Reoperation for bleeding & $5(0.4)$ & $2(0.9)$ & $2(0.7)$ & 0.63 \\
\hline Postoperative stroke & $5(0.4)$ & $4(1.8)$ & $3(1.1)$ & 0.12 \\
\hline Deep sternal infection & $14(1.2)$ & $2(0.9)$ & $7(2.6)$ & 0.18 \\
\hline
\end{tabular}

Data are presented as number (\%). Group N, no prior percutaneous coronary intervention (PCI); Group S, single prior PCl; Group M, multiple prior PCls.

\section{Results}

\section{Baseline Patient Characteristics}

Preoperative patient clinical characteristics in each of the 3 groups are shown in Table 1. Chronic kidney disease and hemodialysis were more often found in Group M (Group N: $47.2 \%$, Group S: $50.7 \%$, and Group M: $59.9 \%$ for chronic kidney disease $[\mathrm{P}<0.01]$ and Group N: 7.5\%, Group S: 7.6\%, and Group M: $15.8 \%$ for hemodialysis $[\mathrm{P}<0.01])$. The proportion of patients with prior MI was highest in Group S (Group N: 22.0\%, Group S: $40.4 \%$, and Group M: $32.0 \%, \mathrm{P}<0.01)$. Sixty patients $(26.7 \%)$ in Group $\mathrm{S}$ had received an emergency single PCI due to acute coronary syndrome (ACS). After treatment for ACS, they were referred for $C A B G$ due to the revascularization of the remaining coronary lesions. Ejection fraction was lowest in Group M (Group N: $57 \pm 14 \%$, Group S: $57 \pm 14 \%$, and Group M: $54 \pm 14 \%, \mathrm{P}<0.01)$.

Angiographic and operative characteristics are shown in Table 2 and Table 3, respectively. The mean number of sessions of PCI before CABG in Group M was 3.6 \pm 2.1 (range: 2-13). Regarding the indication for CABG, patients in Group $\mathrm{M}$ were more likely to have in-stent restenosis or a combination of de novo stenosis and in-stent restenosis $(\mathrm{P}<0.01)$. Patients in Group $\mathrm{M}$ were less likely to have bypass grafts than those in Group $\mathrm{N}$ or Group $\mathrm{S}$ (Group $\mathrm{N}: 3.2 \pm 1.0$, Group S: $3.0 \pm 1.0$, Group M: $2.8 \pm 0.9, \mathrm{P}<0.01$ ).

\section{Early Outcome}

Postoperative outcomes are shown in Table 4. Unadjusted operative mortality was comparable among the 3 groups (Group N: 1.0\%, Group S: 0.9\%, Group M: 1.8\%, P=0.43). Similarly, the incidences of reoperation for bleeding, post- operative stroke and deep sternal infection were comparable among the 3 groups (Group N: 0.4\%, Group S: 0.9\% and Group M: $0.7 \%$ for reoperation for bleeding $(\mathrm{P}=0.63)$, $0.4 \%, 1.8 \%$ and $1.1 \%$ for stroke $(\mathrm{P}=0.12)$, and $1.2 \%, 0.9 \%$ and $2.6 \%$ for deep sternal infection $(\mathrm{P}=0.18)$, respectively.

\section{Long-Term Outcome}

Clinical follow up was completed in 98\%. Overall, 22 patients $(1.9 \%)$ in Group N, 6 patients $(2.6 \%)$ in Group S and 3 patients $(1.1 \%)$ of group $\mathrm{M}$ were lost to follow up. The median follow-up duration was 8.0 years. Kaplan-Meier analysis showed that the cumulative incidence of all-cause death at 10 years post-CABG was highest in Group M $(16.9 \%, 15.6 \%$, and $26.1 \%$ for Groups N, S, and M, respectively, $\mathrm{P}<0.01)$ (Figure). Similarly, the cumulative incidences of cardiac death and MI at 10 years were highest in Group M (4.9\%, 4.9\%, and $12.9 \%$ for cardiac death, respectively, $\mathrm{P}<0.01$; and $0.5 \%, 0.4 \%$, and $2.6 \%$ for $\mathrm{MI}$, respectively, $\mathrm{P}<0.01)$. In contrast, the incidence of repeat revascularization was similar among the groups $(8.9 \%$, $7.1 \%$, and $11.4 \%$, respectively, $\mathrm{P}=0.09$ ).

\section{Multivariate Analysis by Cox Proportional Hazards Models}

The likelihood of all-cause death was higher in Group M than in Group N (HR 1.45; 95\% confidence interval [CI], 1.10-1.91; $\mathrm{P}<0.01$ ) (Table 5). Between Group $\mathrm{N}$ and Group $\mathrm{S}$, in contrast, the likelihood of all-cause death was not different (HR, 0.87; 95\% CI, 0.61-1.26; P=0.47). In addition, the likelihood of cardiac death and MI were higher in Group M than in Group N (HR, 2.39; 95\% CI, $1.55-3.71 ; \mathrm{P}<0.01$ for cardiac death and HR, $3.65 ; 95 \% \mathrm{CI}$, $1.15-11.5 ; \mathrm{P}=0.03$ for $\mathrm{MI})$. Between Groups $\mathrm{N}$ and $\mathrm{S}$, however, the likelihood of cardiac death and MI were not 

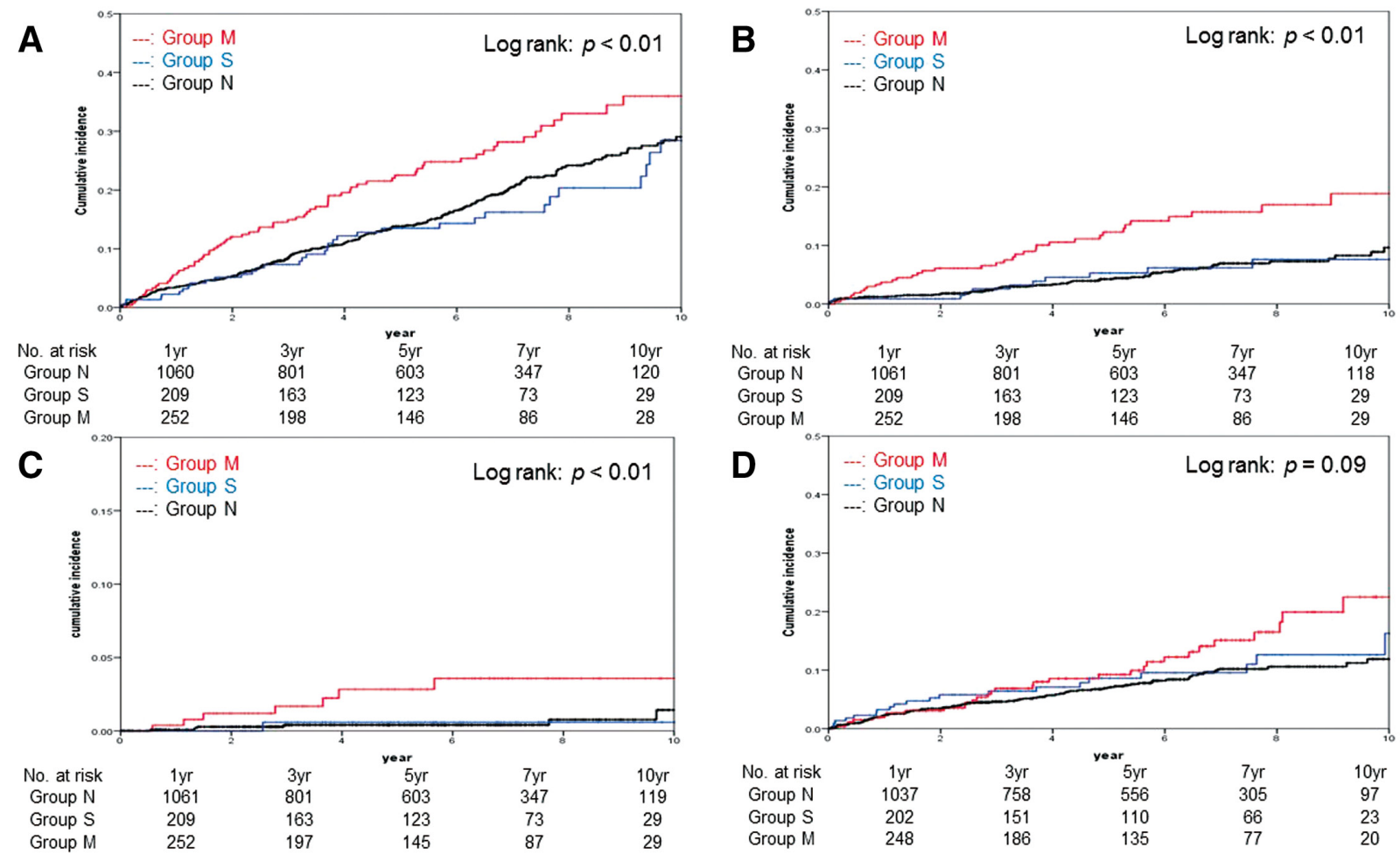

Figure. Kaplan-Meier analysis for cumulative incidences of: (A) all-cause death; (B) cardiac death; (C) myocardial infarction; and (D) repeat revascularization.

\begin{tabular}{|lccc|}
\hline $\begin{array}{l}\text { Table 5. Multivariate Analysis by Cox Proportional Hazard } \\
\text { Models } \\
\text { Outcome }\end{array}$ & HR & P value & $95 \%$ Cl \\
$\begin{array}{l}\text { All-cause death } \\
\text { Group N }\end{array}$ & Ref. & Ref. & Ref. \\
Group S & 0.87 & 0.47 & $0.61-1.26$ \\
Group M & 1.45 & $<0.01$ & $1.10-1.91$ \\
Cardiac death & & & \\
Group N & Ref. & Ref. & Ref. \\
Group S & 0.85 & 0.63 & $0.44-1.65$ \\
Group M & 2.39 & $<0.01$ & $1.55-3.71$ \\
MI & & & \\
Group N & Ref. & Ref. & Ref. \\
Group S & 0.74 & 0.78 & $0.09-6.40$ \\
Group M & 3.65 & 0.03 & $1.15-11.5$ \\
Repeat revascularization & & & \\
Group N & Ref. & Ref. & Ref. \\
Group S & 1.12 & 0.47 & $0.73-1.96$ \\
Group M & 1.47 & 0.08 & $0.96-2.23$ \\
\hline
\end{tabular}

$\mathrm{Cl}$, confidence interval; $\mathrm{HR}$, hazard ratio; $\mathrm{Ml}$, myocardial infarction. Group N, no prior percutaneous coronary intervention (PCI); Group $\mathrm{S}$, single prior PCl; Group M, multiple prior PCls. Adjusted for the following confounders: age, gender, body mass index, hypertension, dyslipidemia, diabetes mellitus, chronic kidney disease, hemodialysis, prior stroke, prior $\mathrm{Ml}$, congestive heart failure, unstable angina, preoperative intra-aortic balloon pumping, urgency of procedure, smoking status, chronic lung disease, peripheral artery disease, atrial fibrillation, left ventricular systolic dysfunction, left main disease, 3-vessel disease, 2-vessel disease, 1-vessel disease, Canadian Cardiovascular Society (CCS) 3-4, New York Heart Association (NYHA) 3-4.

\begin{tabular}{|lccc|}
\hline \multicolumn{2}{|c|}{ Table 6. Causes of Death After CABG } & & \\
Hospital death (total) & Group N & Group S & Group M \\
Infection & 11 & 2 & 5 \\
Sudden death & $6(3.0)$ & $0(0)$ & $4(5.6)$ \\
Aorta related & $3(1.5)$ & $0(0)$ & $0(0)$ \\
Heart failure & $1(0.5)$ & $1(2.7)$ & $0(0)$ \\
Cardiac death (total) & $1(0.5)$ & $1(2.7)$ & $1(1.4)$ \\
Sudden death & 43 & 9 & 32 \\
Heart failure & $25(12)$ & $5(14)$ & $13(18)$ \\
Myocardial infarction & $10(5.0)$ & $2(5.6)$ & $10(14)$ \\
Ventricular arrhythmia & $5(2.5)$ & $1(2.7)$ & $7(9.7)$ \\
Non-cardiac death (total) & $3(1.5)$ & $1(2.7)$ & $2(2.8)$ \\
Malignancy & 148 & 25 & 35 \\
Respiratory failure & $40(20)$ & $3(8.3)$ & $10(14)$ \\
Infection & $6(5.0)$ & $6(17)$ & $5(6.9)$ \\
Cerebrovascular & $30(15)$ & $7(19)$ & $7(9.7)$ \\
Trauma & $14(6.9)$ & $0(0)$ & $2(2.8)$ \\
Renal failure & $5(2.5)$ & $0(0)$ & $0(0)$ \\
Liver failure & $4(2.0)$ & $2(5.6)$ & $0(0)$ \\
Aortic aneurysm/dissection & $2(1.0)$ & $0(0)$ & $0(0)$ \\
Gastrointestinal & $4(2.0)$ & $0(0)$ & $0(0)$ \\
Others & $6(3.0)$ & $1(2.7)$ & $1(1.4)$ \\
Unknown & $13(6.4)$ & $1(2.7)$ & $3(4.2)$ \\
\hline
\end{tabular}

Data are presented as $\mathrm{n}(\%)$. Group N, no prior percutaneous coronary intervention (PCl); Group S, single prior PCl; Group M, multiple prior PCls. 
different (HR, 0.85; 95\% CI, 0.44-1.65; $\mathrm{P}=0.63$ and $\mathrm{HR}$, $0.74 ; 95 \% \mathrm{CI}, 0.09-6.40 ; \mathrm{P}=0.78)$. The risk of repeat revascularization was not different among the groups (HR, 1.12; $95 \% \mathrm{CI}, 0.73-1.96, \mathrm{P}=0.47$ for Groups $\mathrm{N}$ and $\mathrm{S}$, and $\mathrm{HR}$, $1.47 ; 95 \% \mathrm{CI}, 0.96-2.23, \mathrm{P}=0.08$ for Groups $\mathrm{N}$ and $\mathrm{M}$ ).

\section{Cause of Death}

During follow up, 310 patients died; the causes of death are shown according to group in Table 6. The specific causes for non-cardiac death included cerebrovascular disease, respiratory failure and renal failure.

\section{Discussion}

We showed a significantly increased long-term risk of death and cardiovascular events in patients with multiple prior PCIs who subsequently underwent primary isolated CABG.

PCI is considered the standard first-line treatment for ischemic heart disease. As new PCI techniques and devices such as drug-coated balloons (DCB) are still being developed, the average number of rounds of PCI that each patient has undergone continues to increase; in many cases, each PCI was performed with a different device.,5, The number of patients with multiple prior PCI before CABG will probably increase in future.

Previous studies have reported an adverse effect of prior PCI before CABG on early and mid-term clinical outcomes. Kinoshita et al, for example, have reported higher rates of surgical mortality in patients who had previous PCI (7.6\% vs. $1.0 \%, \mathrm{P}=0.008) .{ }^{2}$ Thielmann et al has reported that patients with multiple prior PCIs undergoing CABG have a significantly increased risk for in-hospital mortality (adjusted OR, 3.01; 95\% CI, 1.51-5.98; $\mathrm{P}<0.0017$ ) and major adverse cardiac events (adjusted OR, 2.31; 95\% CI, 1.45-3.67; $\mathrm{P}<0.0004){ }^{3}$ Similarly, Massoudy et al have shown in a multicenter analysis that a history of multiple previous PCIs increased in-hospital mortality (adjusted OR, 1.9; CI, 1.3-2.7; $\mathrm{P}=0.0016)$ and the incidence of major adverse cardiac events after subsequent CABG (adjusted OR, 1.5; CI, 1.2-1.9; $\mathrm{P}=0.0019){ }^{4}$

Regarding long-term outcomes, Mannacio et al have demonstrated that a history of PCI before CABG decreased survival at 5 years' follow up. They reported that survival at 3 and 5 years was lower in patients with previous PCI than in no-PCI patients $(97.4 \pm 0.01 \%$ vs. $96.5 \pm 0.02 \%$ and $94.2 \pm 0.03 \%$ vs. $92.1 \pm 0.05 \% ; \mathrm{P}=0.03) .{ }^{7}$

In contrast, several other studies have found no differences in early and mid-term mortality or cardiovascular events between patients undergoing CABG with and without prior PCI. More recently, Biancari et al reported that a history of multiple prior PCIs was not associated with an increased risk of early adverse events in patients undergoing isolated CABG. ${ }^{8}$ Regarding long-term outcomes, Fukui et al found that the survival rate at 7 years postCABG was not different between the stent and no-stent groups $(87.2 \pm 3.2 \%$ vs. $84.8 \pm 2.9 \%, \mathrm{P}=0.47)$, and that the 2 groups had similar rates of freedom from major adverse cardiac and cerebrovascular events at 7 years post-CABG $(78.9 \pm 3.8 \%$ vs. $77.6 \pm 3.3 \%, \mathrm{P}=0.81) .{ }^{9}$ In these studies, it should be noted that investigators divided patients into 2 groups, a group who had received and a group who had not received prior PCI. In our study, in contrast, we divided patients into 3 groups: a no prior PCI group, a single prior PCI group and a multiple prior PCIs group. We found comparable risks of all-cause death and cardiovascular events between the no prior PCI group and the single prior PCI group. Taken together with previous findings, our results may suggest that multiple prior PCIs is associated with higher risks of long-term death and cardiovascular events, whereas a single prior PCI is not.

The reasons for the adverse effects of multiple prior PCIs on outcomes have not been clarified, but several possible influences of PCI have been considered. First, multiple coronary stents might cause coronary endothelial injury with intimal hyperplasia and stimulation of platelet and neutrophil adhesion, leading to decreased graft patency. ${ }^{10,11}$ In addition, the use of cardiopulmonary bypass might amplify inflammatory reactions locally and/or systemically. ${ }^{10,11}$ Second, multiple coronary stents may cause more distant anastomosis of target vessels. In cases of in-situ arterial grafting, we have no choice but to use a more distal site for the arterial graft. This might affect coronary runoff and the patency rate of the bypass grafts. ${ }^{3}$

In our study, preoperative LVEF was lowest in Group N. One possible reason for this is that multiple prior PCI can cause side-branch obstruction, leading to compromised collateral blood flow and myocardial injury. However, a subset of patients in the Group M had high operative risk, and in such 'high-risk' patients, PCI is sometimes inevitable even if CABG would be preferable. In the 2018 European Society of Cardiology/European Association for Cardio-Thoracic Surgery Guidelines on myocardial revascularization, repeat PCI is recommended as the first-line treatment for recurrent ischemia after PCI; In contrast, in patients with recurrent episodes of diffuse in-stent restenosis in large vessels - and in those with associated multivessel disease, especially in the presence of other complex lesions such as chronic total occlusions - CABG should be considered before a new PCI attempt. ${ }^{12}$ In every case, the operating institution's Heart Team should carefully evaluate the choice between CABG and PCI.

\section{Study Limitations}

Our study has several limitations. First, this study was a retrospective and observational study at a single center. Therefore, selection bias might exist. Second, some potentially relevant data such as SYNTAX score and graft patency were not collected from all patients and so were not included in this study. These data might have had some influence on the outcomes. Third, patients with LV systolic dysfunction sometimes have concurrent ischemic mitral regurgitations. Patients who underwent concomitant mitral valve surgeries were not enrolled in the present study. In future, we must consider a study design including patients with ischemic mitral regurgitations.

\section{Conclusions}

Postoperative mortality after CABG was not different among patients with no prior PCI, single prior PCI and multiple prior PCIs. Long-term, however, multiple prior PCIs were associated with higher risks of death and cardiovascular events after the perioperative period. The incidence of repeat revascularization after $\mathrm{CABG}$ was low regardless of the history of single/multiple PCI.

\section{Sources of Funding}

The authors did not receive any funding for this study. 


\section{Disclosures}

The authors have no conflicts of interest to declare.

\section{IRB Information}

This study was approved by the institutional review board of Kokura Memorial Hospital (reference number: 20031201).

\section{Data Availability}

Due to the nature of this research, participants in this study did not agree for their data to be shared publicly, so supporting data is not available.

\section{References}

1. O’Brien SM, Feng L, He X, Xian Y, Jacobs J, Badhwar V, et al. The Society of Thoracic Surgeons 2018 Adult Cardiac Surgery Risk Models: Part 2-Statistical methods and results. Ann Thorac Surg 2018; 105: 1419-1428.

2. Kinoshita T, Asai T, Murakami Y, Takashima N, Hosoba S, Nishimura O, et al. Impact of previous PCI on hospital mortality after off-pump coronary artery bypass grafting in diabetic patients with multivessel disease. Innovations (Phila) 2009; 4: 334-339.

3. Thielmann M, Leyh R, Massoudy P, Neuhauser M, Aleksic I, Kamler M, et al. Prognostic significance of multiple previous percutaneous coronary interventions in patients undergoing elective coronary artery bypass surgery. Circulation 2006; 114(Suppl I): I-441-I-447.

4. Massoudy P, Thielmann M, Lehmann N, Marr A, Kleikamp G, Malezka A, et al. Impact of prior percutaneous coronary interven- tion on the outcome of coronary artery bypass surgery: A multicenter analysis. J Thorac Cardiovasc Surg 2009; 137: 840-845.

5. Thygesen K, Alpert JS, Jaffe AS, Chiatman BR, Bax JJ, Morrow $\mathrm{DA}$, et al. Fourth universal definition of myocardial infarction (2018). J Am Coll Cardiol 2018; 72: 2231 - 2264.

6. Kufner S, Joner M, Schneider S, Tolg R, Zrenner B, Repp J, et al. Neointimal modification with scoring balloon and efficacy of drug-coated balloon therapy in patients with restenosis in drugeluting coronary stents: A randomized controlled trial. JACC Cardiovasc Interv 2017; 10: 1332-1340.

7. Mannacio V, Di Tommaso L, De Amicis V, Lucchetti V, Pepino $\mathrm{P}$, Musumeci $\mathrm{F}$, et al. Previous percutaneous coronary interventions increase mortality and morbidity after coronary surgery. Ann Thorac Surg 2012; 93: 1956-1962.

8. Biancari F, Dalén M, Ruggieri VG, Demal T, Gatti G, Onorati $\mathrm{F}$, et al. Prognostic impact of multiple prior percutaneous coronary interventions in patients undergoing coronary artery bypass grafting. J Am Heat Assoc 2018; 7: e010089.

9. Fukui T, Tanaka S, Takanashi S. Previous coronary stents do not increase early and long-term adverse outcomes in patients undergoing off-pump coronary artery bypass grafting: A propensity-matched comparison. J Thorac Cardiovasc Surg 2014; 148: $1843-1849$.

10. Lazar HL. Detrimental effects of coronary stenting on subsequent coronary artery bypass surgery: Is there another flag on the field? J Thorac Cardiovasc Surg 2009; 138: 276-277.

11. Wan IY, Arifi AA, Wan S, Yip JH, Sihoe AD, Thung KH, et al. Beating heart revascularization with or without cardiopulmonary bypass: Evaluation of inflammatory response in a prospective randomized study. J Thorac Cardiovasc Surg 2004; 127: 1624-1631.

12. Neumann FJ, Sousa-Uva M, Ahlsson A, Alfonso F, Banning AP, Benedetto U, et al. 2018 ESC/EACTS Guidelines on myocardial revascularization. Eur Heart J 2019; 40: 87-165. 